\title{
FAKTOR-FAKTOR YANG BERHUBUNGAN DENGAN KEJADIAN KECELAKAAN KERJA PADA PEKERJA BAGIAN PRODUKSI PT.HILON SUMATERA
}

\author{
Aswida Novrida Singarimbun ${ }^{1}$, Dameria Gultom ${ }^{2}$ \\ ${ }^{1}$ Fakultas Kesehatan Masyarakat, Universitas Prima Indonesia, Medan \\ 2 Dosen Fakultas Kesehatan Masyarakat, Universitas Prima Indonesia, Medan \\ E-mail : aswidanovrida@gmail.com \\ DOI : https://doi.org/10.35451/jkg.v2i1.183
}

\begin{abstract}
A work accident is something that is not desirable which can cause losses that harm the company and workers. Based on the results of the preliminary survey, at PT. Hilon Sumatera there were many workers who experienced work accidents such as needle punctures, pinched machines, slips due to negligence of workers, in a hurry, slippery floors, out of focus, and sleepiness. Quantitative research design withdesign Cross Sectional with the aim to determine the factors associated with the incidence of workplace accidents in production workers in PT. Hilon Sumatera with a population of 65 people. The sampling technique used is the total population, all populations are sampled. Retrieving data using a questionnaire measuring instrument. Data analysis was carried out by univariate analysis and bivariate analysis (Test Chi-Square) with a significance level of $p$-value $=0.05$. The results showed that the workload with a $p$ value was $0.043<0.05$, ergonomics with a $p$ value of $0.017<0.05$, Housekeeping with a $p$ value of $0.044<0.05$, and the availability of PPE with a $p$ value of 0.000 $<0.05$. The conclusion of this study is that workload, ergonomics, housekeeping, and the availability of personal protective equipment have a relationship with workplace accidents. It is recommended to companies to provide personal protective equipment in accordance with the needs of workers, place material for production materials in accordance with the capacity of the workspace, and improveinspection housekeeping.
\end{abstract}

Keywords : Workload, Ergonomics, Housekeeping, Availability of Personal protective equipment, Work Accidents

\section{Pendahuluan}

Kejadian kecelakaan merupakan sesuatu yang tidak dikehendaki yang dapat merugikan perusahaan maupun pekerja, terhambatnya kegiatan, gangguan produksi, yang berakibatkan gagal tercapainya suatu kemajuan dan standar lingkungan kerja. Kecelakaan disebakan oleh dua penyebab, yaitu penyebab langsung dan penyebab tidak langsung. Penyebab langsung disebabkan oleh perilaku manusia tidak aman dan Kondisi lingkungan kerja yang tidak aman, sedangkan Penyebab tidak langsung ini dapat melibatkan unsurunsur seperti material yang digunakan, peralatan yang dilibatkan, lingkungan tempat bekerja, serta juga orang atau pekerja lain di sekitarnya (Salami, dkk, 2016).

Hal ini sejalan dengan penelitian yang dilakukan oleh Damayanti dan Ramandhani (2018) tentang kecelakaan kerja pada industri baja X di Gresik, bahwa kecelakaan kerja yang terjadi 
Jurnal Kesehatan Masyarakat \& Gizi, e-ISSN: 2655-0849

Vol. 2 No.1 Edisi Mei-Oktober 2019

https://ejournal.medistra.ac.id/index.php/JKG

Received: 05 Oktober 2019 :: Accepted: 14 Oktober 2019 :: Published: 31 Oktober 2019

disebabkan oleh perilaku tidak aman terkait dengan karakteristik individu adalah usia, masa, dan tingkat pendidikan yang rendah. Kondisi tidak aman meliputi kondisi ruang produksi alat dan bahan produksi tidak aman dan penggunaan alat pelindung diri yang tidak adekuat.

Beberapa penelitian menyebutkan faktor yang berhubungan dengan kecelakaan kerja. Pada penelitian Siregar (2014) terhadap pekerja di PT. Aqua Golden Mississippi Bekasi menyatakan bahwa ada hubungan antara housekeeping dengan kecelakaan kerja hal ini disebabkan oleh kurang kondusifnya area kerja yang mana akan menyebabkan semakin tingginya kecelakaan kerja.

Pada penelitian Sulhinayatillah (2017) tentang kecelakaan kerja di PT.PP London Sumatera Indonesia Tbk, terdapat hubungan antara masa kerja, penggunaan alat pelindung diri, perilaku karyawan, lingkungan kerja terhadapat kejadian kecelakaan kerja.

Data BPJS ketenagakerjaan menunjukkan pada tahun 2015 terjadi kecelakaan kerja sebanyak 110.285 kasus, pada tahun 2016 sejumlah 105.182 kasus, dan sampai bulan agustus tahun 2017 terjadi kecelakaan kerja sebanyak 80.492 kasus (BPJS Ketenagakerjaan, 2016).

Badan Penyelenggara jaminan Sosial (BPJS) Sumatera Utara, di wilayah Medan Belawan terdapat data statistik 1.094 kasus, Tanjung morawa sebanyak 1.218 kasus dan Medan Kota sebanyak 484 kasus dengan daya yang ada maka jumlah kecelakaan kerja yang terjadi di Medan Menjadi berkisar 15 kasus setiap harinya (Pekuwali, 2017).
PT.Hilon Sumatera merupakan perusahaan yang bergerak dalam bidang tekstil. Ruang lingkup perusahaan ini adalah memproduksi bantal, guling, carded fiber, High Density Padding, bantalan keras, lembaran serat fiber dan selimut kapas. Alat yang digunakan dalam proses produksi berupa mesin maka diperlukan keterampilan dan pengawasan terhadap penggunaannya, sehingga karyawan dituntut untuk hati-hati agar tidak terjadi kecelakaan kerja yang dapat merugikan pekerja maupun perusahaan.

Berdasarkan hasil saat survey pendahuluan, menurut info dari perusahaan dalam 5 tahun terakhir terdapat beberapa pekerja yang mengalami kejadian kecelakaan kerja seperti tertusuk jarum, terjepit, terpeleset, tersayat pisau, terpotong, dikarenakan oleh kelalaian pekerja yang tidak mematuhi standart operasional prosedur, terburu-buru, lantai licin, tidak fokus, dan pekerja yang mengantuk.

Berdasarkan hal diatas, penulis tertarik untuk meneliti faktor-faktor yang berhubungan dengan kejadian kecelakaan kerja pada pekerja bagian produksi PT. Hilon Sumatera.

\section{Metode Penelitian}

Penelitian ini menggunakan metode penelitian kuantitatif dengan rancangan cross sectional, Penelitian ini dilakukan di wilayah produksi PT.Hilon Sumatera, Jl. Jl. Jamin Ginting KM.11 No.64A Medan dan dilaksanakan pada bulan Maret 2019. Populasi dalam penelitian ini adalah seluruh pekerja di bagian produksi PT.Hilon Sumatera sebanyak 65 orang. Pengumpulan data diperoleh dengan melakukan penyebaran kuesioner kepada pekerja bagian produksi PT.Hilon Sumatera. Data 
dianalisis dengan menggunakan uji Chi-

Square untuk melihat hubungan antara variabel bebas dengan variabel terikat dengan nilai $\mathrm{p}$ value $<0,05$.

\section{Hasil Penelitian}

Analisis Univariat

Tabel 1. Distribusi Responden Berdasarkan Karakteristik Pekerja Di PT.Hilon Sumatera

\begin{tabular}{llcc}
\hline No. & \multicolumn{1}{c}{$\begin{array}{c}\text { Karakteristik } \\
\text { Pekerja }\end{array}$} & Jumlah & Presentase \\
\hline $\mathbf{1}$ & Umur & & \\
& Muda $<30$ & 34 & 52,3 \\
& Tua $\geq 30$ & 31 & 47,7 \\
\hline \multicolumn{2}{l}{ Total } & 65 & 100,0 \\
\hline $\mathbf{2}$ & Jenis Kelamin & 52 & \\
& Laki-Laki & 13 & 80,0 \\
& Perempuan & $\mathbf{6 5}$ & $\mathbf{1 0 0 , 0}$ \\
\hline $\mathbf{3}$ & Total & & \\
& Pendidikan & 1 & 1,5 \\
& SD & 2 & 3,1 \\
& SMP & 58 & 89,2 \\
& SMA/SMK & 2 & 3,1 \\
& D-3 & 2 & 3,1 \\
\hline & S-1 & $\mathbf{6 5}$ & $\mathbf{1 0 0 , 0}$ \\
\hline $\mathbf{4}$ & Total & & \\
& Masa kerja & 27 & 41,5 \\
& Baru <5 Tahun & 38 & 58,5 \\
\hline & Lama $\geq 5$ Tahun & $\mathbf{6 5}$ & $\mathbf{1 0 0 , 0}$ \\
\hline
\end{tabular}

Berdasarkan Tabel 1, pada kategori umur dapat diketahui bahwa responden yang berumur muda $<30$ tahun terdapat 34 responden $(52,3 \%)$, dan umur tua $\geq 30$ tahun terdapat 31 responden $(47,7 \%)$. Pada kategori jenis kelamin laki-laki terdapat 52 responden (80\%) dan pada jenis kelamin perempuan terdapat 13 responden (20\%). Pada kategori pendidikan responden yang berpendidikan SD terdapat 1 responden
$(1,5 \%)$, pendidikan SMP terdapat 2 responden $(3,1 \%)$, pendidikan SMA/SMK terdapat 58 responden $(89,2 \%)$, pendidikan D-3 terdapat 2 responden $(3,1 \%)$, dan pendidikan S-1 terdapat 2 responden $(3,1 \%)$. Pada Kategori Masa kerja dapat diketahui bahwa masa kerja baru terdapat 27 responden $(41,5 \%)$, dan masa kerja lama terdapat 38 responden $(58,5 \%)$.

Tabel 2. Distribusi Faktor Yang Berhubungan Dengan Kecelakaan Kerja

\begin{tabular}{lcc}
\hline Faktor Kecelakaan Kerja & n & Presentase \\
\hline Beban Kerja & 3 & 4,6 \\
\hline Beban kerja Ringan & 13 & 20,0 \\
Beban Kerja Sedang & 49 & 75,4 \\
Beban Kerja Berat & & \\
\hline Ergonomi & 51 & 78,5 \\
\hline Tidak Ergonomi & 14 & 21,5 \\
Ergonomi & &
\end{tabular}




\begin{tabular}{lcc}
\hline Housekeeping & & \\
\hline Tidak kondusif & 54 & 83,1 \\
kondusif & 11 & 16,9 \\
\hline Ketersediaan Alat Pelindung Diri & & 29,2 \\
\hline Masker & 19 & 47,7 \\
Masker dan Sarung Tangan & 31 & 23,1 \\
Masker, Sarung tangan, Sepatu & 15 & \\
boots & & \\
\hline
\end{tabular}

Berdasarkan tabel 2, dapat dilihat bahwa pada kategori beban kerja responden yang menjawab bahwa beban kerja berat sebanyak 49 orang $(75,4 \%)$, responden yang menjawab beban kerja sedang sebanyak 13 orang $(20,0 \%)$ dan responden yang menjawab beban kerja ringan sebanyak 3 orang (4,6\%). Pada kategori Ergonomi responden yang menjawab bahwa pekerja tidak ergonomi sebanyak 51 orang $(78,5 \%)$, dan responden yang menjawab pekerja ergonomi sebanyak 14 orang $(21,5 \%)$. Pada kategori Housekeeping dapat dilihat bahwa responden yang menjawab bahwa lingkungan kerja tidak kondusif sebanyak 45 orang $(69,2 \%)$, dan responden yang menjawab lingkungan kerja kondusif sebanyak 20 orang $(30,8 \%)$. Pada kategori Ketersediaan alat Pelindung Diri dapat dilihat bahwa responden yang bekerja dengan menggunakan alat pelindung diri berupa masker sebanyak 19 orang $(29,2 \%)$, responden yang bekerja dengan menggunakan alat pelindung diri berupa masker dan sarung tangan sebanyak 31 orang $(47,7 \%)$, dan pekerja yang bekerja dengan alat pelindung diri masker, sarung tangan, dan sepatu boots sebanyak 15 orang $(23,1 \%)$.

\section{Analisis Bivariat}

Tabel 3. Hubungan faktor Beban Kerja dengan Kecelakaan Kerja DiPT. Hilon Sumatera

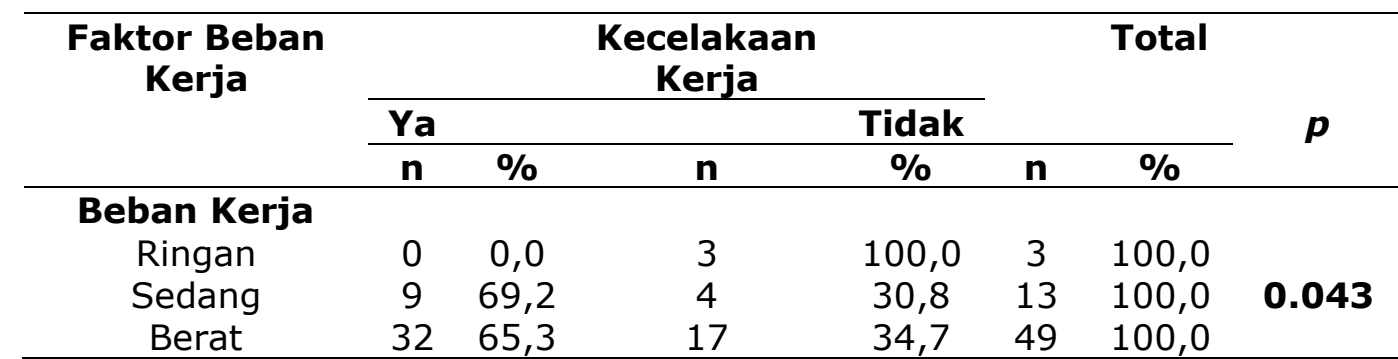

Berdasarkan tabel 3, hasil analisa bivariat menunjukkan dari 3 responden $(4,6 \%)$ yang memiliki beban kerja ringan tidak pernah mengalami kecelakaan kerja, sebanyak 13 responden (20\%) yang memiliki beban kerja sedang diantaranya yang pernah mengalami kecelakaan kerja terdapat 9 orang $(69,2 \%)$ yang pernah mengalami kecelakaan kerja dan 4 orang $(30,8 \%)$ yang tidak pernah mengalami kecelakaan kerja, dan sebanyak 49 responden $(75,4 \%)$ yang memiliki beban kerja berat diantaranya yang prnah mengalami kecelakaan kerja terdapat 32 orang $(65,3 \%)$ dan 17 orang $(34,7 \%)$ yang tidak pernah mengalami kecelakaan kerja.

\section{Tabel 4. Hubungan faktor Ergonomi dengan Kecelakaan Kerja Di PT. Hilon Sumatera}




\begin{tabular}{|c|c|c|c|c|c|c|c|}
\hline \multirow{3}{*}{$\begin{array}{l}\text { Faktor } \\
\text { Ergonomi }\end{array}$} & \multicolumn{4}{|c|}{ Kecelakaan Kerja } & \multirow{2}{*}{\multicolumn{2}{|c|}{ Total }} & \multirow{3}{*}{$\boldsymbol{p}$} \\
\hline & \multicolumn{3}{|l|}{$\mathbf{Y a}$} & Tidak & & & \\
\hline & $n$ & $\%$ & $\mathbf{n}$ & $\%$ & $\mathbf{n}$ & $\%$ & \\
\hline \multicolumn{8}{|l|}{ Erqonomi } \\
\hline Tidak Ergonomi & 36 & 70,6 & 15 & 29,4 & 51 & 100,0 & 0.017 \\
\hline Ergonomi & 5 & 35,7 & 9 & 64,3 & 14 & 100,0 & \\
\hline
\end{tabular}

Berdasarkan tabel 4, dari 51 responden $(78,5 \%)$ yang tidak ergonomi, diantaranya 36 orang $(70,6 \%)$ pernah mengalami kecelakaan kerja dan 15 orang $(29,4 \%)$ tidak pernah mengalami kecelakaan kerja, dan sebanyak 14

Tabel 5. Hubungan faktor Housekeeping dengan Kecelakaan Kerja Di PT. Hilon Sumatera

Faktor
Housekeeeping

\begin{tabular}{cccccccc} 
& \multicolumn{6}{c}{ Tidak } & P \\
\cline { 2 - 6 } & $\mathbf{n}$ & $\%$ & $\mathbf{n}$ & $\%$ & $\mathbf{n}$ & $\%$ & \\
\hline Housekeeeping & & & & & & & \\
$\begin{array}{c}\text { Tidak kondusif } \\
\text { kondusif }\end{array}$ & 4 & 68,5 & 17 & 31,5 & 54 & 100,0 & $\mathbf{0 . 0 4 4}$ \\
\hline
\end{tabular}

Berdasarkan tabel 5, dari 54 responden $(83,1 \%)$ yang menyatakan housekeeping tidak kondusif, diantaranya 37 orang $(68,5 \%)$ pernah mengalami kecelakaan kerja dan 17 orang $(31,5 \%)$ tidak pernah mengalami kecelakaan kerja, dan sebanyak 11 responden $(21,5)$ yang ergonomi, diantaranya 5 orang $(35,7 \%)$ pernah mengalami kecelakaan kerja dan 9 orang $(64,3 \%)$ tidak pernah mengalami kecelakaan kerja. responden $(16,9 \%)$ yang menyatakan housekeeping kondusif diantaranya 4 orang $(36,4 \%)$ pernah mengalami kecelakaan kerja dan 7 orang $(63,6 \%)$ tidak pernah meengalami kecelakaan kerja.

Tabel 6. Hubungan faktor Ketersediaan APD dengan Kecelakaan Kerja Di PT. Hilon Sumatera

\begin{tabular}{|c|c|c|c|c|c|c|c|}
\hline \multirow{3}{*}{$\begin{array}{l}\text { Faktor } \\
\text { Ketersediaan } \\
\text { APD }\end{array}$} & \multicolumn{4}{|c|}{ Kecelakaan Kerja } & \multicolumn{2}{|r|}{ Total } & \multirow{3}{*}{$p$} \\
\hline & \multicolumn{2}{|l|}{$\mathbf{Y a}$} & \multicolumn{2}{|r|}{ Tidak } & \multirow[b]{2}{*}{$\mathbf{n}$} & \multirow[b]{2}{*}{$\%$} & \\
\hline & $\mathbf{n}$ & $\%$ & $\mathbf{n}$ & $\%$ & & & \\
\hline $\begin{array}{l}\text { Ketersediaan } \\
\text { APD }\end{array}$ & & & & & & & \\
\hline Masker & 15 & 78,9 & 4 & 21,1 & 19 & 100,0 & \\
\hline $\begin{array}{l}\text { Masker dan } \\
\text { Sarung tangan }\end{array}$ & 24 & 77,4 & 7 & 22,6 & 31 & 100,0 & 0.000 \\
\hline $\begin{array}{c}\text { Masker, sarung } \\
\text { tangan dan sepatu } \\
\text { boots }\end{array}$ & 2 & 13,3 & 13 & 86,7 & 15 & 100,0 & \\
\hline
\end{tabular}

Berdasarkan tabel 6, dari 19 responden $(29,2 \%)$ yang memiliki ketersediaan alat pelindung diri berupa masker, diantaranya 15 orang( $78,9 \%)$ pernah mengalami keecelakaan kerja dan 4 orang $(21,2 \%)$ tidak pernah mengalami kecelakaan kerja, dari 31 responden $(47,7 \%)$ yang memiliki ketersediaan 
Received: 05 Oktober 2019 :: Accepted: 14 Oktober 2019 :: Published: 31 Oktober 2019

alat pelindung diri berupa masker dan sarung tangan diantaranya 24 orang $(77,4 \%)$ pernah mengalami kecelakaan kerja dan sebanyak 7 orang $(22,6 \%)$ tidak pernah mengalami kecelakaan kerja, dan dari 15 responden ( $23,1 \%$ ) yang memiliki ketersediaan alat

\section{Pembahasan}

\section{Hubungan faktor Beban Kerja dengan Kecelakaan Kerja}

Berdasarkan uji statistik yang dilakukan dengan menggunakan uji Chi Square di peroleh $p$-value sebesar 0.043 ( $p$-value $<0,05$ ) yang menyatakan bahwa terdapat hubungan yang signifikan antara beban kerja dengan kecelakaan kerja.

Menurut (Mutia, 2014) Berat ringannya beban kerja yang ditanggung oleh pekerja dapat digunakan untuk menentukan lama pekerja dapat melakukan aktivitasnya. Semakin berat beban kerja, maka semakin singkat waktu seseorang untuk bekerja.

Penelitian ini sejalan dengan penelitian yang dilakukan oleh Tamaka, dkk (2017) beban kerja yang berlebih akan sangat rentan dengan kecelakaan kerja. Tingginya beban kerja dipengaruhi oleh ketidaksesuaian waktu istirahat yang disediakan dan juga dikarenakan oleh tugas tambahan lainnya.

Beban kerja berat dipengaruhi oleh kemampuan otot. Jika otot kehilangan kemampuan untuk menahan beban, maka pekerja tidak akan mampu untuk mengangkat beban tersebut, sehingga beban yang diangkat dapat beresiko untuk terjatuh dan pada akhirnya dapat menyebabkan terjadinya kecelakaan kerja (Kurniawan, dkk, 2018)

Tingginya beban kerja di PT.Hilon Sumatera salah satunya dikarenakan oleh permintaan pesanan yang kadang mendadak dan harus diselesaikan dalam waktu yang cepat. Pekerjaan yang pelindung diri berupa masker, sarung tangan, dan sepatu boots, diantaranya 2 orang $(13,3 \%)$ pernah mengalami kecelakaan kerja dan sebanyak 13 orang $(86,7 \%)$ tidak pernah mengalami kecelakaan kerja.

memiliki beban berat membutuhkan istirahat yang sering dan waktu kerja yang pendek agar terhindar dari kelelahan yang kemudian dapat menimbulkan kecelakaan kerja.

\section{Hubungan faktor Ergonomi dengan Kecelakaan Kerja}

Posisi yang ergonomi merupakan salah satu penunjang untuk pekerja berproduktifitas dengan baik, apabila pekerja tersebut nyaman dalam bekerja, maka pekerja tersebut akan mengurangi resiko cedera otot dan terhindar dari kecelakaan kerja (Listautin, 2017)

Berdasarkan uji statistik yang dilakukan dengan menggunakan uji Chi Square di peroleh $p$-value sebesar 0.017 ( $p$-value $<0,05)$ yang menyatakan bahwa terdapat hubungan yang signifikan antara ergonomi dengan kecelakaan kerja.

Saat bekerja Pekerja PT.Hilon Sumatera bekerja dengan sikap atau posisi kerja duduk maupun berdiri yang cukup lama, dan dalam posisi tubuh yang membungkuk. Hal ini dikarenakan oleh pekerja menyesuaikan postur badannya dengan alat kerja yang digunakan. Pekerja dibagian gudang mengangkat beban dengan posisi membungkuk, sehingga beresiko untuk terjadinya kelelahan otot dan dapat mengakibatkan beban yang diangkat jatuh yang kemudian dapat menimbulkan kecelakaan kerja. 
Received: 05 Oktober 2019 :: Accepted: 14 Oktober 2019 :: Published: 31 Oktober 2019

Upaya yang dapat dilakukan oleh perusahaan dengan menyarankan kepada pekerja untuk melakukan peregangan dan menerapkan prinsip keergonomian yaitu memperhatikan jarak ruang kerja, meminimalisir titik beban, dan menggunakan alat kerja yang sesuai dengan dimensi tubuh.

\section{Hubungan faktor Housekeeping dengan Kecelakaan Kerja}

Suma'mur (2009) dalam Pardede (2017) housekeeping berupaya untuk menempatkan peralatan kerja yang tepat, sesuai dan benar, mengutamakan proses kerja berlangsung aman dan agar kegiatan dapat berlangsung optimal, efisien dan efektif serta pencegahan kecelakaan kerja.

Berdasarkan uji statistik yang dilakukan dengan menggunakan uji Chi Square di peroleh $p$-value sebesar 0.044 ( $p$-value $<0,05$ ) yang menyatakan bahwa terdapat hubungan yang signifikan antara housekeeping dengan kecelakaan kerja.

Program Housekeeping yang terdapat di PT.Hilon Sumatera kurang berjalan dengan baik. Terdapat bahan sisa material produksi yang berserakan di ruangan penjahitan dan pet botol, sehingga dapat memungkinkan pekerja dapat tersandung maupun terpeleset pada saat bekerja.

Upaya yang dapat dilakukan oleh pihak perusahaan dan manajemen untuk mengendalikan kecelakaan kerja salah satunya adalah dengan melakukan inspeksi housekeeping yang dilakukan secara rutin agar tempat kerja lebih terkontrol.

\section{Hubungan faktor Ketersediaan APD dengan Kecelakaan Kerja}

Berdasarkan uji statistik yang dilakukan dengan menggunakan uji Chi Square di peroleh $p$-value sebesar 0.000 ( $p$-value
$<0,05)$ yang menyatakan bahwa terdapat hubungan yang signifikan antara ketersediaan APD dengan kecelakaan kerja.

Ketersediaan Alat Pelindung Diri merupakah keharusan sebuah perusahaan untuk para tenaga kerja agar dapat meminimalkan anggaran perusahaan untuk biaya pengobatan untuk para karyawan yang mengalamikecelakaan atau penyakit akibat kerja (Hamza, 2013)

Menurut Suma'mur (2013) Alat pelindung diri harus, nyaman dipakai, tidak mengganggu pelaksanaan pekerjaan dan memberikan perlindungan efektif terhadap berbagai macam bahaya yang dihadapi.

PT.Hilon Sumatera menyediakan Alat Pelindung Diri yang disesuaikan dengan resiko bahaya yang ada di unit kerja masing-masing berupa masker pada unit penjahitan, masker dan sarung tangan pada unit produksi bahan, dan masker, sarung tangan, sepatu boots pada unit pet botol. Contohnya pada unit kerja pet botol yang pekerjaanya menggunakan mesin dan berhubungan dengan benda tajam dengan kondisi lingkungan kerja yang licin, maka perusahaan menyediakan Alat Pelindung Diri yang Lengkap. Namun, pada unit penjahitan hanya disediakan masker sehingga pekerja masih rentan terkena kecelakaan kerja berupa tertusuk jarum.

\section{Kesimpulan}

Berdasarkan hasil penelitian dan pembahasan yang telah diuraikan, maka dapat diambil beberapa kesimpulan sebagai berikut.

1. Ada hubungan antara faktor Beban Kerja dengan kejadian kecelakaan 
Jurnal Kesehatan Masyarakat \& Gizi, e-ISSN: 2655-0849

Vol. 2 No.1 Edisi Mei-Oktober 2019

https://ejournal.medistra.ac.id/index.php/JKG

Received: 05 Oktober 2019 :: Accepted: 14 Oktober 2019 :: Published: 31 Oktober 2019

kerja pada pekerja bagian produksi PT. Hilon Sumatera.

2. Ada hubungan antara faktor Ergonomi dengan kejadian kecelakaan kerja pada pekerja bagian produksi PT. Hilon Sumatera.

3. Ada hubungan antara faktor Housekeeping dengan kejadian kecelakaan kerja pada pekerja bagian produksi PT.Hilon Sumatera

4. Ada hubungan antara faktor Ketersediaan Alat Pelindung Diri dengan kejadian kecelakaan kerja pada pekerja bagian produksi PT.Hilon Sumatera.

\section{Daftar Pustaka}

BPJS Ketenagakerjaan (2016). Jumlah Kecelakaan Kerja di Indonesia Masih Tinggi. Artikel. https://www.bpjsketenagakerjaan .go.id/berita/5769/Jumlahkecelakaan-kerja-diIndonesiamasih-tinggi.html

Damayanti, R. dan Ramandhani, E. (2018). Gambaran Kecelakaan Kerja Di Industri Baja X Gresik Indonesia, Vol 2(2), pp. 152-161.

Hamza, A. (2013). Faktor Yang Berhubungan Dengan Penggunaan Alat Pelindung Diri Pada Karyawan Unit Produksi PTPN x (PERSEERO) Pabrik Gula Arasoe Bone Tahun 2013, 21, pp. 528-535.

Kurniawan, dkk (2018). HUBUNGAN PENGETAHUAN, KELELAHAN, BEBAN KERJA FISIK, POSTUR TUBUH SAAT BEKERJA, DAN SIKAP PENGGUNAAN APD DENGAN KEJADIAN KECELAKAAN KERJA (Studi Pada Aktivitas Pengangkatan Manual di Unit Pengantongan Pupuk Pelabuhan Tanjung Emas Semarang), Jurnal Kesehatan Masyarakat (eJournal), Vol 6(4), pp. 393-401.

Listautin (2017). Hubungan Penggunaan Alat Pelindung Diri, Aktivitas Kerja Berulang Dan Ergonomi Terhadap Kecelakaan Kerja Pada Tenaga Kerja Bongkar PT. Jambi Waras
Tahun 2016, Vol 6(02), pp. 86-92.

Mutia, M. (2014). Pengukuran Beban Kerja Fisiologis dan Psikologis Pada Operator Pemetikan Teh Dan Operator Produksi Teh Hijau Di PT Mitra Kerinci. Jurnal Fakultas Teknik Industri Universitas Andalas Padang, Vol 13(1).

Pardede, S. T. A. (2017) 'Faktor Yang Berhubungan Dengan Kecelakaan Kerja Pada Pekerja Bagian Loading Ramp Di Pabrik Negeri Lama Satu Pt. Hari Sawit Jaya Kabupaten Labuhan Batu Tahun 2017', pp. 91-110.

Pekuwali, D. (2017) Angka Kecelakaan Kerja Sumbagut, News Artikel. http://www.medanbisnisdaily.com /news/read/2017/07/21/311657/ kasus-kecelakaan-kerja-disumbagut-masih-tinggi/

Salami, dkk (2016). Kesehatan Dan Keselamatan Lingkungan Kerja. Gadjah Mada University Press : Yogyakarta.

Siregar, D. (2014). Faktor-Faktor Yang Berhubungan Dengan Kecelakan Ringan Di PT.Aqua Golden Mississippi Bekasi tahun 2014. Universitas Islam Negeri Syarif Hidayatullah Jakarta.

Sulhinayatillah (2017). Faktor-Faktor Yang Berhubungan Dengan Kejadian Kecelakaan Kerja Pada Karyawan Bagian Produksi Di Pt. Pp London Sumatra Indonesia Tbk, Palangisang Crumb Rubber Factory, Bulukumba Sulawesi Selatan 2017, pp. 1-166.

Suma'mur (2013) Higiene Perusahaan Dan Kesehatan Kerja (HIPERKES). Sagung Seto : Jakarta.

Tamaka, dkk, (2017) .Hubungan antara beban kerja dan perilaku aman dengan cedera tertusuk jarum suntik pada perawat di Rumah Sakit Bhayangkara tk. III Manado, Media Kesehatan, Vol 9(3). 